\title{
Chronic Ulcer on Flank Region as First Manifestation of Crohn's Disease
}

\author{
Ho Sung Kim (D), Seok Kyung In (D), Byeong Seok Kim (D), Jin Hyung Park (D), Hyung Suk Yi (D), Hong II Kim (D), \\ Yoon Soo Kim (D), Hyo Young Kim (1D \\ Department of Plastic and Reconstructive Surgery, Kosin University College of Medicine, Busan, Korea
}

\begin{abstract}
Crohn's disease is difficult to diagnose owing to its varied symptoms, among which fistulae are a late-stage symptom that appears mainly in the form of a perianal fistula. A patient who was previously healthy without clinical history visited our hospital with an ulcer of unknown cause at the right flank and gluteal region. Using computed tomography (CT) and colonoscopy, we diagnosed the ulcer as an enterocutaneous fistula caused by Crohn's disease and successfully treated it with general surgery. In young, lean men with skin lesions of unknown cause, a CT or colonoscopy test may be useful for diagnosing underlying gastrointestinal problems.
\end{abstract}

Keywords: Crohn disease; Enterocutaneous fistula; Epidemiology; Skin ulcer

\section{Introduction}

\begin{abstract}
Abscesses of the flank and superior gluteal region are generally caused by ruptured epidermal cysts, furuncles, and in recent literature, by non-tuberculosis mycobacterial (NTM) infections [1]. In addition, untreated gastrointestinal (GI) tract problems such as appendicitis and peritonitis may cause a fistula in the gluteal or anal region $[2,3]$.

Crohn's disease is an inflammatory bowel disease that occurs mainly in the third decade of life and is characterized by abdominal pain, diarrhea, and weight loss due to GI tract inflammation [4,5]. Fistulae are a complication of Crohn's disease, often occurring in the form of a perianal fistula [6]. The exact pathogenesis of Crohn's disease is not known, and the diagnosis is based on the patient's medical history, physical examination results, and laboratory, serological, radiological, endoscopic, and histological findings [7]. For this reason, diagnosis is difficult and often delayed. We report a case of a skin fistula due to Crohn's disease in a 29-year-old man who was previously healthy and had no clinical history of unknown soft tissue infection. For participation in this study, written informed consent was obtained from the patient, and the study was conducted in accordance with the principles of the Declaration of Helsinki.
\end{abstract}

\section{Case}

A 29-year-old man visited our hospital because of pain and ulcers in the right flank and upper gluteal region (Fig. 1). He had no GI tract symptoms such as abdominal pain, diarrhea, constipation, or bloody stool; nor had he any known family history of the sort. He first noticed the skin abscess 4 months before his hospital visit. The skin abscess progressed into an ulcer of unknown cause in the right flank region and tun-

\section{Case Report}

Received: March 25, 2020

Revised: April 26, 2020

Accepted: May 8, 2020

\section{Corresponding author:} Hyo Young Kim, M.D.

Department of Plastic and Reconstructive Surgery, Kosin University College of Medicine, 262 Gamcheon-ro, Seo-gu, Busan 49267, Korea

Tel: +82-51-990-6131

Fax: +82-51-990-3005

E-mail: hose3290@naver.com

This is an Open Access article distributed under the terms of the Creative Commons Attribution Non-Commercial License (https://creativecommons.org/licenses/by-nc/4.0/) which permits unrestricted non-commercial use, distribution, and reproduction in any medium, provided the original work is properly cited.

C) 2020 Korean Wound Management Society 


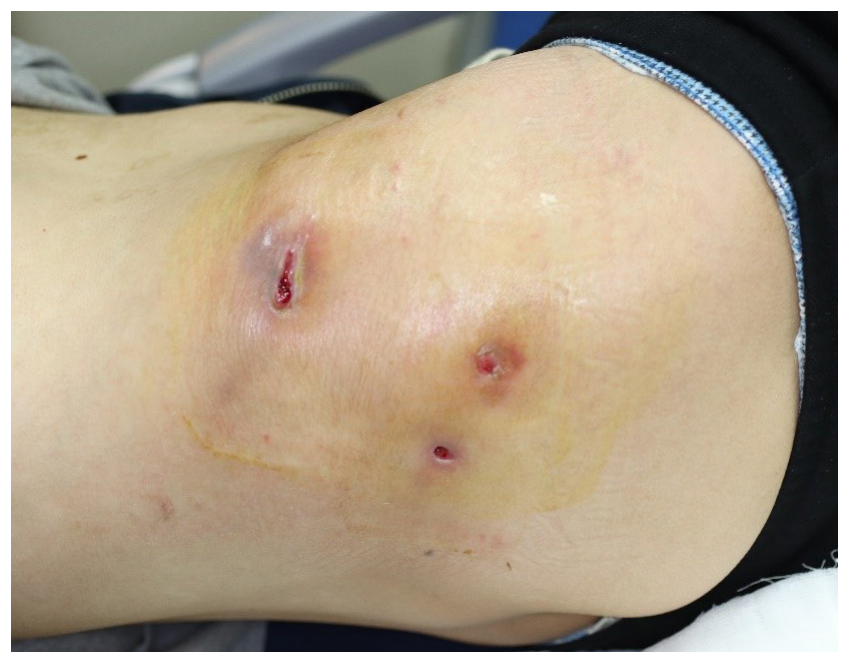

Fig. 1. Clinical photograph of the patient at first hospital visit. The ulcerative lesion on the right lateral side of the superior gluteal region.

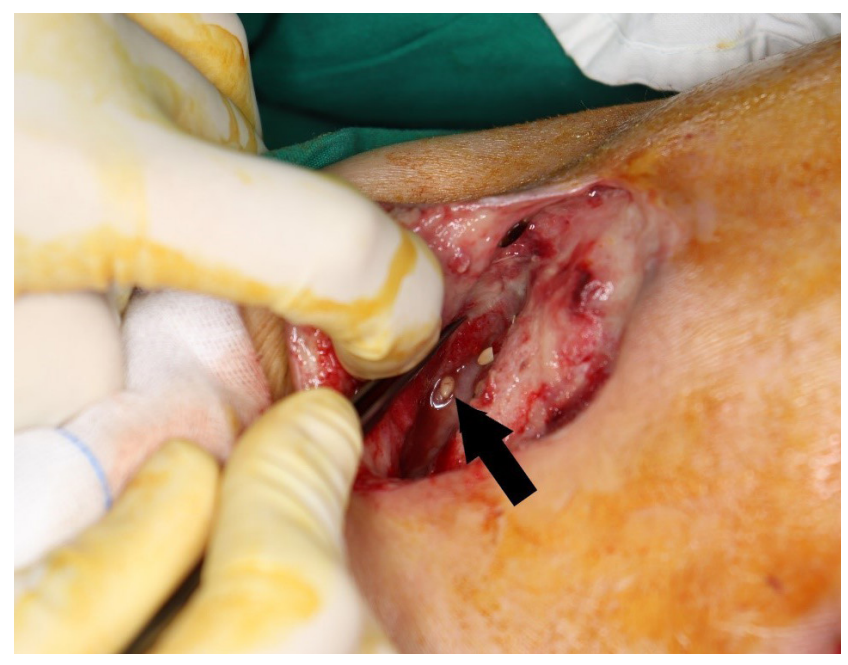

Fig. 2. Clinical photograph of the irrigation procedure. The black arrow indicates undigested food (fruit seeds) in the lesion.

neled to the upper gluteal region. The patient underwent debridement and direct closure, antibiotic treatment, and wound dressing in a local medical center, but the symptoms were not relieved. Hence, the patient visited our hospital for further evaluation. At the time of his visit, he presented with wounds oozing with a large amount of pus that caused a foul odor. The open wounds tunneled into the subcutaneous layer. Laboratory tests revealed an elevated erythrocyte sedimentation rate of $45 \mathrm{~mm} / \mathrm{hr}$ (normal range: $<20 \mathrm{~mm} / \mathrm{hr}$ ) and a high sensitivity C-reactive protein level of $2.82 \mathrm{mg} / \mathrm{dL}$ (normal range: $<0.75$ $\mathrm{mg} / \mathrm{dL}$ ). No other specific findings were obtained, and his vital signs were stable. As the skin ulcer was caused by an unknown
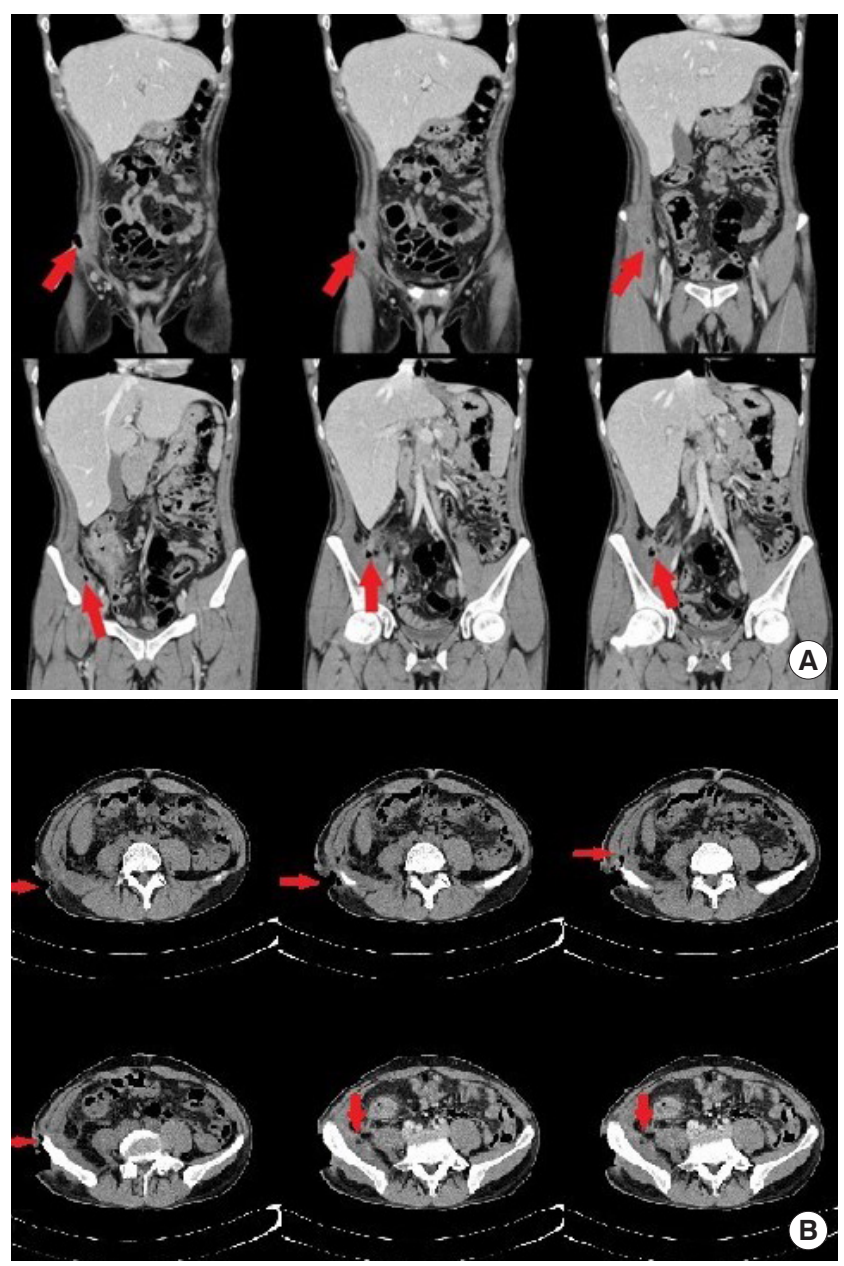

Fig. 3. An abdominal CT scan obtained after undigested food was found. (A) Coronal and (B) axial views of the CT scan. The red arrow indicates the enterocutaneous fistula. CT, computed tomography.

infection, we performed daily irrigation in the operating room and administered intravenous antibiotics. NTM tests were performed at the same time as the wound cultures to identify the cause; however, the results were negative.

Despite the continuous irrigation, the wounds did not improve significantly, and on the seventh day of irrigation, undigested food was found at the wound site (Fig. 2).

The patient had consumed the food found. The suspected infection was considered to be due to a fistula between the skin ulcer and the GI tract. Abdominal computed tomography (CT) revealed a tract from the ascending colon to the skin (Fig. 3). Colonoscopy was performed after consulting a gastroenterologist (Fig. 4). Colonoscopy revealed a cobblestone appearance and stricture of the sigmoid colon. The fistula was not found because of luminal narrowing. Based on the clinical symptoms 


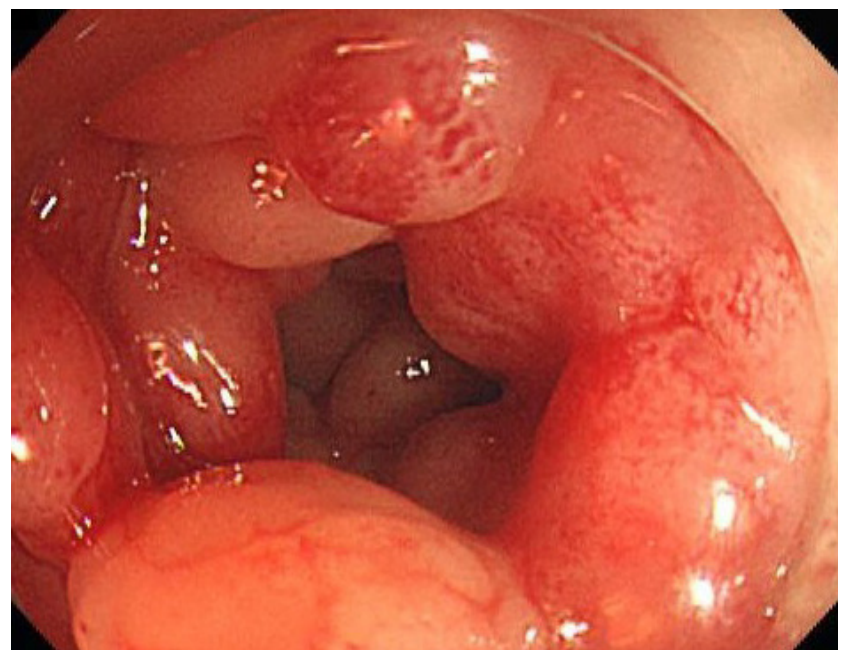

Fig. 4. A colonoscopy photograph showing cobblestone appearance of the colon.

and colonoscopy result, the diagnosis of Crohn's disease was confirmed. To treat the enterocutaneous fistula, laparoscopic right hemicolectomy and sigmoidectomy (to address the stricture of the sigmoid colon) were performed by a GI surgeon. As the GI problem was resolved, the open wounds were closed with advancement flaps (Fig. 5). After fully explaining the purpose of the study to the patient, consent was obtained for the study and case presentation.

\section{Discussion}

In this case, the patient was admitted because of an ulcerative wound of the skin without other GI symptoms. The patient was thereby diagnosed with Crohn's disease. Crohn's disease can be confirmed using colonoscopy and biopsy; however, diagnosis is often delayed because of the varied manifestations of the symptoms, and diagnosis is also difficult because symptoms often present only after adulthood [5].

The most frequent initial symptom of Crohn's disease is diarrhea, followed by anal lesion, abdominal pain, and rectal bleeding $[5,8]$. Conversely, enterocutaneous fistulae are rare, as noted in a previous case study by Kelly et al., in which only four of 239 cases presented with skin fistulae [9].

Fistulae are most commonly found in the perianal region, followed by the groins and then the abdominal walls $[6,10]$. In addition, skin fistulae from Crohn's disease appear after significant progression of Crohn's disease. In this case, the ulcer was in the flank and gluteal area, and the patient had no GI symptoms. Therefore, it was difficult to assume whether the fistula

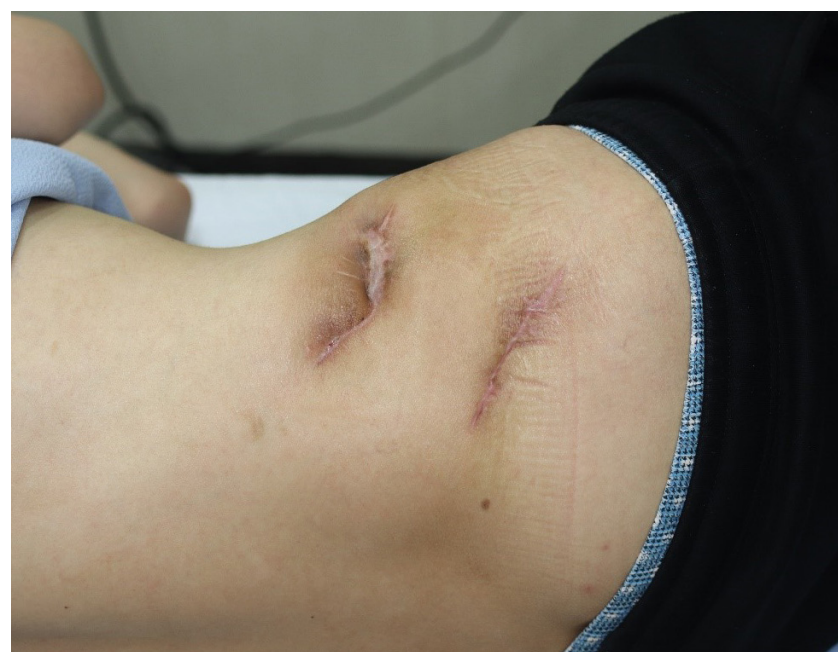

Fig. 5. Two-month postoperative clinical photograph. The healed skin on the site of the fistula wound.

was related to a GI tract disorder. For this reason, it took more than 4 months for the patient to be diagnosed with Crohn's disease.

In Crohn's disease, the fistula originates from the epithelial defects that develop during chronic inflammation. The epithelial-to-mesenchymal transition (EMT) and intestinal epithelial cells penetrate into the deeper tissue layer, which causes tissue damage to the body surface and creates a connection. Afterward, fistula formation and growth are further facilitated by the presence of EMT inducers such as the transforming growth factor and pathogen-associated molecular patterns [11].

In addition to Crohn's disease, various diseases such as diverticular disease and acute pancreatitis can form enterocutaneous fistulae that open out onto the skin while the main cause is surgical complications $[12,13]$. Enterocutaneous fistulae can occur in any disease, but with low incidence, it is difficult to diagnose.

Hawker et al. [14] studied enterocutaneous fistulae in Crohn's disease. Most of these fistulae were of ileal origin while the next most frequently observed originated from the colon. In the present case, the fistula originated from the colon. In most of the previous cases, the patients presented with malnutrition. As the fistula manifests late in the course of the disease, it is often diagnosed after Crohn's disease and weight loss had progressed. In the present case, the patient's height was $177.7 \mathrm{~cm}$, weight was $60.7 \mathrm{~kg}$, and body mass index was $19.2 \mathrm{~kg} / \mathrm{m}^{2}$.

Consensus has not yet been reached on optimal management of the enterocutaneous fistula in Crohn's disease. Cur- 
rently, surgical intervention and nutritional and metabolic support are favored over palliative treatment [14].

In conclusion, in young, lean men with chronic skin lesions of unknown origin in the flanks, upper gluteal region, and anal areas, a CT or a colonoscopy test may be useful for the diagnosis of underlying GI problems.

\section{Conflict of interest}

No potential conflicts of interest relevant to this article are reported.

\section{ORCID iDs}

$\begin{array}{ll}\text { Ho Sung Kim } & \text { https://orcid.org/0000-0002-6030-3199 } \\ \text { Seok Kyung In } & \text { https://orcid.org/0000-0003-4346-7949 } \\ \text { Byeong Seok Kim } & \text { https://orcid.org/0000-0003-1375-1092 } \\ \text { Jin Hyung Park } & \text { https://orcid.org/0000-0001-9415-2467 } \\ \text { Hyung Suk Yi } & \text { https://orcid.org/0000-0002-9584-8201 } \\ \text { Hong Il Kim } & \text { https://orcid.org/0000-0002-5505-9945 } \\ \text { Yoon Soo Kim } & \text { https://orcid.org/0000-0002-8073-5511 } \\ \text { Hyo Young Kim } & \text { https://orcid.org/0000-0002-1834-5766 }\end{array}$

\section{References}

1. Moriuchi R, Arita K, Ujiie H, et al. Large subcutaneous abscesses caused by Mycobacterium fortuitum infection. Acta Derm Venereol 2008;88:313-4.

2. Deorah S, Seenu V, Pradeep KK, et al. Spontaneous appendico-cutaneous fistula: a rare complication of acute appendicitis. Trop Gastroenterol 2005;26:48-50.

3. Agrawal V, Prasad S. Appendico-cutaneous fistula: a diag- nostic dilemma. Trop Gastroenterol 2003;24:87-9.

4. Wagtmans MJ, Verspaget HW, Lamers CB, et al. Crohn's disease in the elderly: a comparison with young adults. J Clin Gastroenterol 1998;27:129-33.

5. Van Assche G, Dignass A, Panes J, et al. The second European evidence-based consensus on the diagnosis and management of Crohn's disease: definitions and diagnosis. J Crohns Colitis 2010;4:7-27.

6. Schwartz DA, Loftus EV Jr, Tremaine WJ, et al. The natural history of fistulizing Crohn's disease in Olmsted County, Minnesota. Gastroenterology 2002;122:875-80.

7. Laass MW, Roggenbuck D, Conrad K. Diagnosis and classification of Crohn's disease. Autoimmun Rev 2014;13:46771.

8. Lockhart-Mummery HE, Morson BC. Crohn's disease of the large intestine. Gut 1964;5:493-509.

9. Kelly JK, Preshaw RM. Origin of fistulas in Crohn's disease. J Clin Gastroenterol 1989;11:193-6.

10. McCallum DI, Kinmont PD. Dermatological manifestations of Crohn's disease. Br J Dermatol 1968;80:1-8.

11. Scharl M, Rogler G. Pathophysiology of fistula formation in Crohn's disease. World J Gastrointest Pathophysiol 2014; 5:205-12.

12. Aldridge MC, Francis ND, Glazer G, et al. Colonic complications of severe acute pancreatitis. Br J Surg 1989;76:3627.

13. Evenson AR, Fischer JE. Current management of enterocutaneous fistula. J Gastrointest Surg 2006;10:455-64.

14. Hawker PC, Givel JC, Keighley MR, et al. Management of enterocutaneous fistulae in Crohn's disease. Gut 1983;24: 284-7. 